\title{
Effect of High Molecular Nano-Chitosan Addition on The Impact Strength of Heat Polymerized Polymethyl Methacrylate Denture Base Resin
}

\author{
Ika Devi Adiana \\ Department of Dental Material and Technology \\ Faculty of Dentistry, Universitas Sumatera Utara \\ Medan, Indonesia \\ devi_ika27@rocketmail.com
}

\author{
Trimurni Abidin \\ Department of Conservative Dentistry Faculty of \\ Dentistry, Universitas Sumatera Utara \\ Medan, Indonesia
}

\author{
Lasminda Syafiar \\ Department of Dental Material and Technology \\ Faculty of Dentistry, Universitas Sumatera Utara \\ Medan, Indonesia
}

\begin{abstract}
Addition of reinforcing material to improve the mechanical properties of heat-polymerized polymethyl methacrylate is being developed. One of them is by adding nano-chitosan gel. This study was aimed to investigate the effect of nano-chitosan gel addition on the impact strength of heat-polymerized polymethyl methacrylate denture base resin. Thirty pieces sample of an acrylic plate in size of $50 \times 10 \times 4 \mathrm{~mm}$ were divided into 6 groups: with the addition of nano-chitosan gel at the concentration of 0.25 , 0.50, 0.75, 1.00, 1.50\% and control group. About $2 \mathrm{ml}$ of nano-chitosan gel was added into the mixture of acrylic resin with a $P: L$ ratio $(23 \mathrm{gr}: 10 \mathrm{ml})$. Then, the mixture was inserted into a mold and pressed. The curing process was performed at $74^{\circ} \mathrm{C}$ for 120 minutes and then at $100^{\circ} \mathrm{C}$ for 60 minutes. Acrylic plates were removed from the mold and polished. The impact strength of acrylic resin was measured with Charpy tester and data were analyzed by one-way ANOVA. The result showed that there was a significant difference in impact strength after the addition of nano-chitosan gel in different percentages. The addition of nano-chitosan gel with the concentration of $1.00 \%$ had the best impact strength which is $7.91 \times 10^{-3} \mathrm{~J} / \mathrm{mm}^{2}$. In conclusion, the addition of nano-chitosan gel can be used to increase the impact strength of heat-polymerized polymethyl methacrylate denture base resin.
\end{abstract}

Keywords-denture base, high molecular nano-chitosan, impact strength

\section{INTRODUCTION}

Acrylic resin is a commonly used material in denture base fabrication. The common use of polymethyl methacrylate resin in the fabrication of denture base is due to its several benefits, such as good biological properties, simple manipulation, good dimensional stability, and excellent esthetic, as it resembles the color of oral gingival [1]. In spite of these benefits, the heatpolymerized polymethyl methacrylate possesses several limitations, such as low mechanical properties which leads to the higher occurrence of fracture while falling, and while enduring mastication force in the mouth due to extensive usage [2]. One of the mechanical properties of heat-polymerized polymethyl methacrylate is its impact strength [1]. The fractures of acrylic resin denture base after several years of usage were $68 \%$ due to its impact strength [3].

To improve the mechanical properties of acrylic resin denture base, the addition of reinforcing material is needed. Several types of reinforcing material are chemical, metal, and fiber, but recently, the use of the natural material is increasing. One of the natural reinforcing material is chitosan [4]. According to Petri et al (2007), low molecular-chitosan-modified glass ionomer cement showed that addition of $0.0044 \%$ chitosan could increase the mechanical properties, such as flexural strength and flour release [5].

Chitosan is one of the natural biomaterials that has recently undergone numerous developments as it possesses various medical benefits and is proven safe for human use. Chitosan has several special properties, such as good biocompatibility, biodegradable, mucoadhesion, non-toxicity, non-allergenic, and non-carcinogenic, which leads to its use as a common biomedical application [6].

This study aims to determine the effect of high molecular nano-chitosan in different concentrations to the impact strength of heat-polymerized polymethyl methacrylate.

\section{MATERIALS AND METHODS}

Chitosan gel was fabricated by homogeneously diluting the high molecular nano-chitosan powder, respectively $0.25,0.50,0.75,1.00$ and 1.50 gr into 100 $\mathrm{ml}$ of $1 \%$ acetic acid in beaker glass filled with the magnetic stirrer on the 200-rpm hot plate for 30 minutes. 
The chitosan solution was added with 20 drops of tripolyphosphate (TPP) while being stirred for 1-hour to reach gel consistency. The solution was put in the ultrasonic bath for 20 minutes to break the chitosan materials, then centrifuged for 30 minutes at $3600 \mathrm{rpm}$ to break the chitosan materials into nanoparticles with size $240 \mathrm{~nm}$ (measured with Particle Size Analysis) (Figure 1). The residual gel would be added to heatpolymerized polymethyl methacrylate.

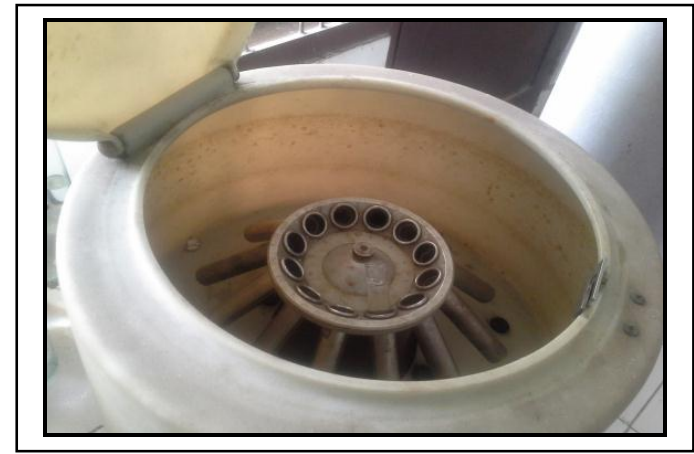

Figure 1. Centrifugation of Chitosan Solution

The study samples were prepared in bars in size of 50x6x4 mm (ISO standard 1567;1999/Amd.1:2003). The total samples were 30 samples, divided into 6 groups, i.e. control group (without the addition of high molecular chitosan addition) and groups with $0.25 \%$, $0.50 \%, 0.75 \%, 1.00 \%$ and $1.50 \%$ chitosan addition.

The mold of heat-polymerized polymethyl methacrylate was fabricated by mixing hard gyps and water $(300 \mathrm{gr}: 90 \mathrm{ml})$ to fill the bottom half of cuvette. Metal plates in size of $50 \mathrm{~mm} \times 6 \mathrm{~mm} \times 4 \mathrm{~mm}$ were implanted in the bottom half of the cuvette with their surfaces aligned to the hard gyps surface and left for setting (Figure 2). The gyps and metal plate surfaces were covered with vaseline, and the top half of cuvette was assembled, before being filled with hard gyps and left for setting. After 45 minutes, the cuvette was assembled, and plates were retrieved. The gyps surface was then applied with cold mould seal.

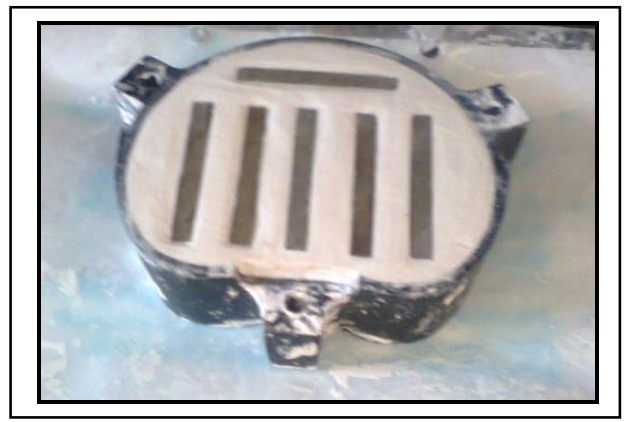

Figure 2. Implantation of metal plates in gyps mixture

To fill the mold, polymer and monomer of heatpolymerized polymethyl methacrylate were mixed with comparison of 23 gr polymer : $10 \mathrm{ml}$ monomer and $2 \mathrm{ml}$ of nano-chitosan gel in respectively $0.25 \%, 0.50 \%$, $0.75 \%, 1.00 \%$ and $1.50 \%$ concentration was added using scale pipe (control group received no addition of chitosan gel), and then stirred slowly. After reaching its dough-stage, the mixture was poured into the mold. Heat-polymerized polymethyl methacrylate was covered with the cellophane sheet, and then the top half of the cuvette was assembled, the cuvette was then pressed with 1000-Psi hydraulic press, and then dissembled. The excess acrylic was removed with lecron carver. The cuvette was re-assembled and was re-pressed with 1200Psi pressure to create maximum contact of top and bottom halves of the cuvette, and fastened with screws. Then curing was performed in several stages. First, cuvette was put in $74^{\circ} \mathrm{C}$ water bath for 120 minutes (Figure 3). Second, the temperature was increased to $100^{\circ} \mathrm{C}$ and left in the water bath for 60 minutes. Then, the cuvette was retrieved from the water bath and left for 30 minutes to cool. The acrylic samples were prepared to the desired sizes.

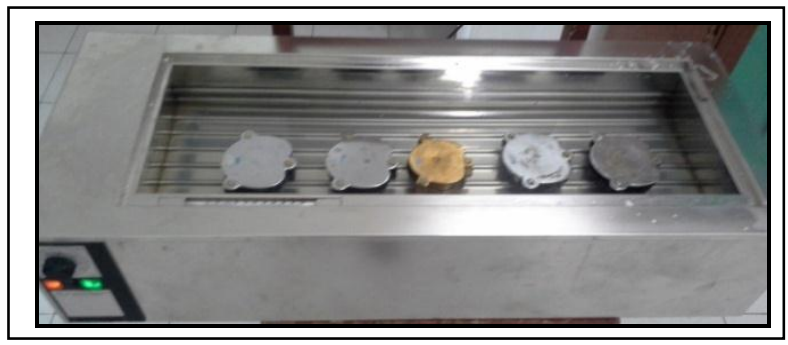

Figure 3. Curing of heat-polymerized polymethyl methacrylate

Impact strength measurement was performed with Charpy tester (Figure 4). The unit of measurement is $\mathrm{J} / \mathrm{mm}^{2}$.

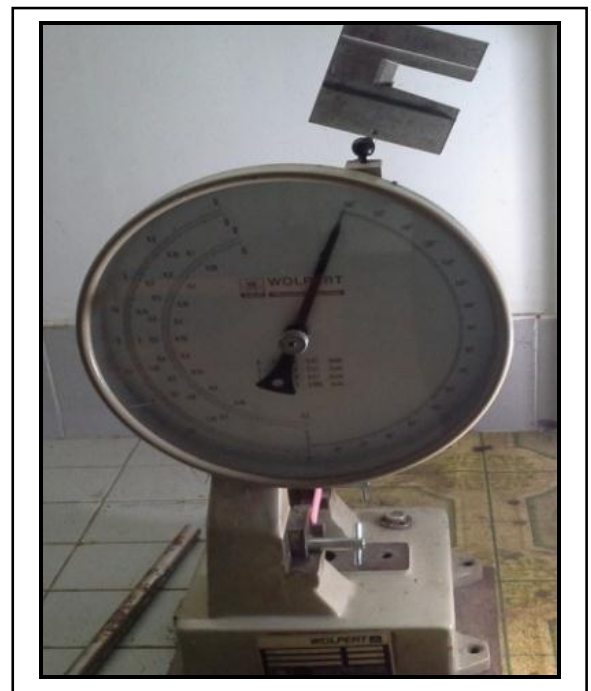

Figure 4. Impact strength tester

\section{RESULTS}

The study resulted in the datum of strength impact changes of three treatment groups. The mean value and standard deviation of impact strength test of all samples with and without the addition of $0.25 \%, 0.50 \%, 0.75 \%$, $1.00 \%$ and $1.50 \%$ high molecular nano-chitosan gel can be observed in Table I. 
TABLE I. MEAN VALUE AND STANDARD DEVIATION OF IMPACT STRENGTH TEST OF HEAT-POLYMERIZED POLYMETHYL METHACRYLATE DENTURE BASE

\begin{tabular}{|c|c|c|c|c|c|c|}
\hline & Control & $\begin{array}{c}\text { Chitosan } \\
\mathbf{0 . 2 5 \%}\end{array}$ & $\begin{array}{c}\text { Chitosan } \\
\mathbf{0 . 5 0 \%}\end{array}$ & $\begin{array}{c}\text { Chitosan } \\
\mathbf{0 . 7 5 \%}\end{array}$ & $\begin{array}{c}\text { Chitosan } \\
\mathbf{1 . 0 0 \%}\end{array}$ & $\begin{array}{c}\text { Chitosan } \\
\mathbf{1 . 5 0 \%}\end{array}$ \\
\hline $\mathbf{X}$ & 5.833 & 5.916 & 6.416 & 6.583 & 7.916 & 6.083 \\
\hline SD & 0.294628 & 0.348608 & 0.475073 & 0.348608 & 0.416667 & 0.631906 \\
\hline
\end{tabular}

Graphic of strength impact value of heatpolymerized polymethyl methacrylate with and without the addition of $0.25 \%, 0.50 \%, 0.75 \%, 1.00 \%$ and $1.50 \%$ nano-chitosan gel can be seen in Figure 5.

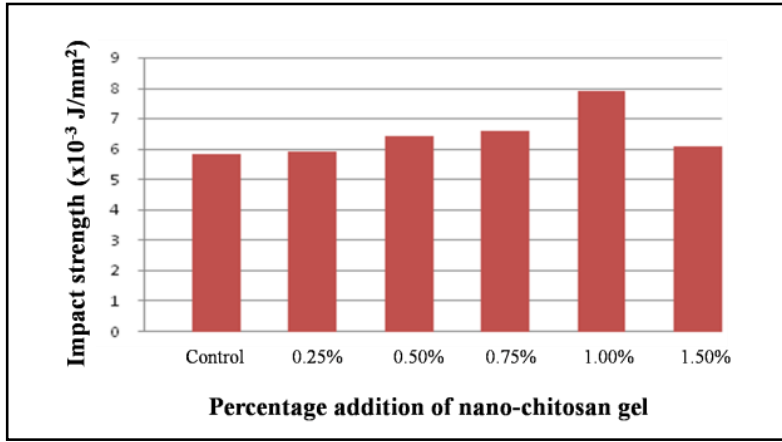

Figure 5. Graphic of impact strength value of heat-polymerized polymethyl methacrylate with and without addition of nano-chitosan gel $0.25 \%, 0.50 \%, 0.75 \%, 1.00 \%$, and $1.50 \%$.

Figure 5 showed that all treatment groups of heatpolymerized polymethyl methacrylate presented changes of impact strength value in each group. Addition of $1 \%$ nano-chitosan gel presented a significant increase of impact strength compared to other treatment groups.

The normality test of this study showed a normal data distribution $(\mathrm{p}>0.05)$. In this study, the effect of $0.25 \%, 0.50 \%, 0.75 \%, 1.00 \%$ and $1.50 \%$ nano-chitosan gel was analyzed with one way ANOVA test, with the significance value of $\mathrm{p}=0$. This proves the effect of $0.25 \%, 0.50 \%, 0.75 \%, 1.00 \%$ and $1.50 \%$ nano-chitosan gel addition to the impact strength of heat-polymerized polymethyl methacrylate.

\section{DISCUSSION}

Results in Table 1 showed the different mean values of the impact strength of heat-polymerized polymethyl methacrylate with and without the addition of $0.25 \%$, $0.50 \%, 0.75 \%, 1.00 \%$, and $1.50 \%$ nano-chitosan gel. Addition of high molecular nano-chitosan was an alternative to increase the impact strength of a heatpolymerized polymethyl methacrylate denture base material, as the particle size of the nano-chitosan material increases its quality, where smaller particles of chitosan create larger surface [7]. The use tripolyphosphate will create ionic bond strengthening the matrix of nano-chitosan [8].

After addition of $1.50 \%$ nano-chitosan gel, the increase of impact strength is lower compared to the addition of $1.00 \%$ nano chitosan gel, this is due to high concentration of high molecular nano-chitosan gel which increases its viscosity compared to other addition of nano-chitosan gel. The higher percentage of chitosan solution is, the higher viscosity of the solution will be, thus, the addition of $1.50 \%$ nano chitosan gel will cause difficulty of gel diffusion to fill the poly (methyl methacrylate) particle space and affect its mechanical properties. In this case, the mechanical strength of the gel is determined by its viscoelasticity [6].

Based on the study conducted by Trong-Ming (2001) to determine the structural changes and thermal properties of PMMA with the addition of 1-15 gr of chitosan, the best modified PMMA-chitosan structure was found in addition of $1 \mathrm{gr}$ chitosan. In this study, the addition of $1.00 \%$ nano-chitosan gel is the optimum concentration to be added in PMMA denture base material.

During the polymerization process, a $0.2-0.5 \%$ of volumetric shrinkage occurs, leading to porosity and crack of the acrylic resin, resulting in a decrease of density and strength of the material [1]. Addition of nano-chitosan gel in a heat-polymerized polymethyl methacrylate denture base material will decrease the amount of porosity. This is consistent with the study of Wen-Chuan et al (2007), which stated that pore-size and porosity of chitosan scaffolds will decrease along with the increase of chitosan concentration [9]. The membranous porosity of chitosan will decrease along with the increase of chitosan concentration.

Amer (2014) stated that during the polymerization process, bonding of polymer chains occurs where $-\mathrm{CH} 3$ in PMMA bonds with $-\mathrm{OH}$ in the chitosan polymer chain. In addition, carbonyl $\mathrm{C}=\mathrm{O}$ cluster in the poly (methyl methacrylate) chain will bond with the NH2 in chitosan. This particular bond will increase the impact strength of heat-polymerized polymethyl methacrylate denture base material caused by the addition of nanochitosan gel. The interaction is illustrated in Figure 6.

The more ionic bond formation found in polymer chain will create a three-dimensional continuous structure that is strong and rigid to certain force or pressure. According to $\mathrm{Li} \mathrm{Z}$ et al (2016), the mechanical strength of composite nanofibrous membrane increase along with the increase of chitosan/PMMA concentration [11]. This is similar to the result of this study which shows that addition of nano-chitosan gel on heat-polymerized polymethyl methacrylate denture base material increases its mechanical properties, one of them is the impact strength.

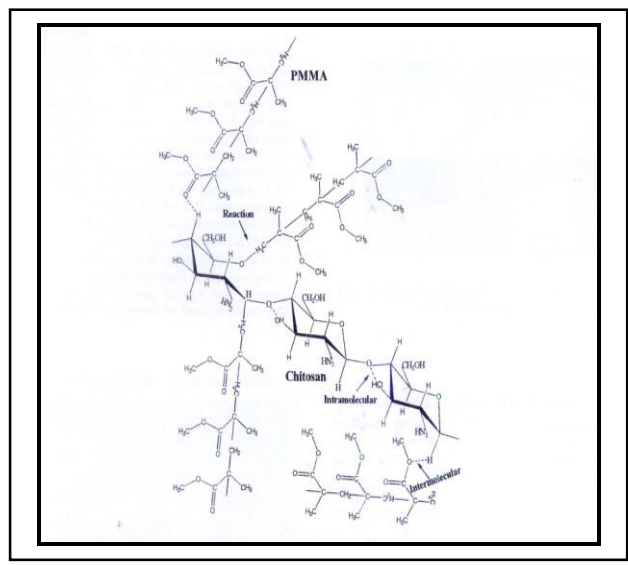

Figure 6. Interaction of chitosan/PMMA [10] 
Based on this study results, it can be concluded that there is an effect of $0.25 \%, 0.50 \%, 0.75 \%, 1.00 \%$ and $1.50 \%$ nano-chitosan gel addition in the heatpolymerized polymethyl methacrylate to its impact strength. Addition of $1.00 \%$ nano-chitosan gel in the heat-polymerized PMMA denture base material is the most compatible consistency to be used as reinforcing material to increase its impact strength.

\section{REFERENCES}

[1] K.J. Anusavice, C. Shen, H.P. Rawls, Phillips' Science of dental materials, $12^{\text {th }}$ ed., USA: Elsevier Saunders, 2013, pp. 735-744.

[2] Z. Raszewski, D. Nowakowska, "Mechanical properties of hot curing acrilyc resin after reinforced with different kinds of fibers," Int. J. Biomedical Materials Research, vol. 1(1), pp. 913, June 2013.

[3] T.K. Mowade, S.P. Dange, M.B. Thakre, V.D. Kamble, "Effect of fiber reinforcement on impact strength of heat polymerized polymethyl methacrylate denture base resin: In vitro study and SEM analysis," J. Adv. Prosthodont., vol. 4, pp. 30-36, 2012.

[4] N. Flores-Ramirez, G. Luna-Barcenas, S.R. Vasquez-Garcia, J. Munoz-Saldana, E.A. Elizalde-Pena, R.B. Gupta, I.C. Sanchez, J. Gonzalez-Hernandez, B. Garcia-Gaitan, F. Villasenor-Ortega, "Hybrid natural-synthetic chitosan resin: thermal and mechanical behavior," J. Biomater. Sci. Polymer Edn., vol. 19, no. 2, pp. 259-273, 2008.
[5] D.F.S. Petri, J. Donega, A.M. Benassi. "Preliminary study on chitosan modified glass ionomer restoratives," J. Dent. Materials, vol. 23, pp. 1004-1014, June 2006.

[6] P. Sugita, T. Wukisari, A. Sjahriza, A Wahyono. "Kitosan sumber biomaterial masa depan,” Bogor. IPB Press, pp. 27, 82 $108,125,2009$

[7] Z. Li-Ming, S. Lu-E, Z. Zhi-Liang, C, Jian-Min, S. Dong-Dong, J. Yang, T. Zhen-Xing. "Preparation and application of chitosan nanoparticles and nanofibers," Brazilian Journal of Chemical Engineering, vol. 28(3), pp. 353-362, July-September 2011.

[8] D. Yuliani, "Pembuatan emulsi kitosan cangkang blankas melalui metode gelasi ionik terhadap kitosan nano dengan menggunakan freezer-dryer," Tesis. Medan. Fakultas Matematika dan Ilmu Pengetahuan Alam Universitas Sumatera Utara, pp. 9-12, 2013.

[9] H. Wen-Chuan, C. Chih-Ponng, L. Shang-Ming, Morphology and characterization of 3D micro-porous structured chitosan scaffolds for tissue enginerering," Colloids and Surfaces B. Biointerfaces, vol. 57, pp. 250-255, February 2007.

[10] Z.J.A. Amer, J.K. Ahmed, S.F. Abbas, "Chitosan/PMMA bioblend for drug release applications," Int. J. Eng. and Tech, vol. 4(5), pp. 318-324, May 2014.

[11] Z. Li, T. Li, L. An, P. Fu, C. Gao, Z. Zhang, "Highly efficient chromium (VI) adsorbtion with nanofibrous filter paper prepared through electrospinning chitosan/polymethylmethacrylate composite" J. Carbohydrate Polymer, vol. 137, pp. 119-126, October 2015. 